\title{
Quantification of cadmium transfers in crayfish: Marked differences between natural predation of field contaminated prey and force-feeding exposure
}

\author{
O. Simon and A. Boudou ${ }^{1}$
}

\author{
Institute of Protection and Nuclear Safety, DPRE/SERLAB, Laboratory of Experimental \\ Radioecology, CEN Cadarache, bâtiment 186, BP. 1, 13108 Saint-Paul-lez-Durance, France \\ ${ }^{1}$ Laboratory of Ecophysiology and Ecotoxicology of Aquatic Systems, UMR 5805, \\ University of Bordeaux 1, Station Marine d'Arcachon, 33120 Arcachon, France
}

\begin{abstract}
The bicaccumulation of heavy metals depends on the uptake via both contaminated food and water, however the relative importance of these two routes often remains uncertain. The contributions of the direct and trophic routes for cadmium (Cd) and zinc ( $\mathrm{Zn}$ ) contamination is unknown for most freshwater organisms. The aim of this work was to investigate $\mathrm{Cd}$ and $\mathrm{Zn}$ trophic bioaccumulation in crayfish Astacus astacus from Corbicula fluminea exposed in-situ at a contaminated site for 30 days. Zn concentrations in the crayfish after trophic exposure were found to be independent of the $\mathrm{Cd}$ contamination level of $C$. fluminea, demonstrating the homeostic regulation of this essential element. In contrast, $\mathrm{Cd}$ bioaccumulation at the whole body level of $A$. astacus reflected the level of contamination in the prey; $\mathrm{Cd}$ accumulated particularly in the digestive gland. The average transfer was be close to 5 \% after 30 days' exposure. However, we a force feeding exposure experiment performed in order to control the mass of prey consumed by the crayfish resulted in a much higher level of accumulation,. after a 48 hour exposure, the trophic transfer was $58 \%$. The results of both experimental approaches show the importance of the trophic contamination route as $\mathrm{q}$ source of $\mathrm{Cd}$ and indicate that ingested $\mathrm{Cd}$ may be transferred via the hemolymph to other tissues, especially the digestive gland.
\end{abstract}

\section{L.NTRODUCTION}

Trophic contamination is considered dominant with regard to the bioaccumulation of certain metals, for example methylmercury, leading to extremely significant cumulative transfers towards the predatory species in freshwater ecosystems [ 1,2 ]. However there is uncertainty relating to the modalities of cadmium (Cd) accumulation in organisms [ 3-5], several authors indicating that direct transfer is dominant [ 6,7] whereas others have found thatprey/predator transfers are more significant [ 8-11]. In situ, it is very difficult to quantify the respective contributions of the two routes; the bioaccumulation being the result of both the contributions from thedirect and trophic routes, and in parallel, the depuration prosesses (mainly fecal and urinary elimination).

Two complementary approaches (experiment I \& II) were carried out: (i) the first experiment, using natural predation conditions between a bivalve Corbicula fluminea and the crayfish Astacus Astacus, was based on 30 days' trophic transfer in the laboratory via daily ingestion of control and contaminated prey, the clams being previously exposed in the field using a caging procedure at a reference site (control prey) and a polluted site (contaminated prey); (ii) the second, more reductionistic approach used a force feeding technique in order to quantify under controlled conditions the transfer of cadmium after a single ingestion of contaminated C. fluminea soft body. .

The results presented in this paper show an analysis of the bioaccumulation of cadmium in the principal organs and tissue compartments of the crayfish, and the trophic transfer rates for the two experimental approaches. The very marked differences observed between the $\mathrm{Cd}$ transfer rates from natural predation conditions and the force feeding exposure led to the development of complementary experiments in order to identify the principal controlling factors. 


\section{MATERIALS AND METHODS}

\section{I Experiment I: Field exposure of prey and natural trophic transfer}

C. fluminea mass of the soft body $=0.354 \pm 0.014 \mathrm{~g}$ - were contaminated in situ, (river Lot, France) ata reference station and a contaminated station. After 30 days of exposure, the average tissue concentrations were $174 \pm 8 \mathrm{ng}-\mathrm{Cd} \cdot \mathrm{g}^{-1}$, fresh weight (fw) (reference station) and $3075 \pm 135 \mathrm{ng}-\mathrm{Cd} \cdot \mathrm{g}^{-1}, \mathrm{fw}$ (contaminated station) in the soft body of $C$. fluminea. These levels illustrate the strong accumulation capacity of these clams. They were then used to feed the crayfish.

Crayfish - $9 \mathrm{~cm}$, mass=10.6 $\pm 0.42 \mathrm{~g}$, fw -, placed in individual enclosures were exposed to contamination via the consumption of either contol or contaminated $C$. fluminea during 30 days. The feet ration of each crayfish was one soft body of $C$. flumineq per day, leading to the ingestion of $1850 \pm 90 \mathrm{ng}$. $\mathrm{Cd} /$ craysfish (consumption of control preys) or $32650 \pm 1400 \mathrm{ng}-\mathrm{Cd},(17.6 \mathrm{x}$ control level) for the consumption of the contaminated preys. The quantification of the food contributions is of primary importance for the calculation of the trophic transfer rates .

The mass of $C$. fluminea soft bodies introduced into the enclosures were measured daily, and to avoid possible direct contamination via excreted $\mathrm{Cd}, 2 / 3$ of the water volume was regularly replaced.

\section{II Experiment II: Force feeding experiments}

The force feeding was performed by the introduction of a homogenate of $C$. fluminea directly into the stomach of the crayfish by using a syringe connected to a capillary glass tube, under binocular magnifying glass.. Corbicula were contaminated in the laboratory under controlled conditions during 10 days of exposure.

After homogenisation of the soft bodies of Corbicula fluminea, the average concentration accumulated was $1462 \pm 20 \mathrm{ng}-\mathrm{Cd} \cdot \mathrm{g}^{-1}$, fw, corresponding to an average of $1155 \pm 78 \mathrm{ng}-\mathrm{Cd}$, in introduced into the stomachs of the 12 crayfish (18-months-old males, $m=14.6 \pm 0.5 \mathrm{~g}$, fw). The evolution of the Cd distribution in the principal tissue compartments was analyzed at 5 times: 0,20 ', $1 \mathrm{~h}, 3 \mathrm{~h}$ and 18 hours.

\section{III Cd organotropism, Cd determination and Data analysis}

6 organ samples were taken from each crayfish to determine Cd concentrations: oesophagus and stomach, gills, intestine, digestive gland: hepatopancreas (HP), green gland, tail muscle. The rest of the body (RB), principally fragments of carapace, was mechanically ground. Moreover, during experiment II, we took a part of the hemolymphatic compartment. Biological samples were then stored frozen $\left(-20^{\circ} \mathrm{C}\right)$.

$\mathrm{Cd}$ concentrations in the biological samples were determined by atomic absorption spectrometry . Varian AA 400 with a GTA 96 graphite tube atomizer and autosampler, detection limit: $0.1 \mu \mathrm{g} . \mathrm{L}^{-1}-\mathrm{Cd}$.

Means and standard errors of the mean (SEM, p<0.05) were calculated with at least 3 replicates for all parameters. The effects of the Factor considered - Corbicula control and Corbicula contaminated consumption - on the Cd bioaccumulation were studied by a general one-way ANOVA $(p<0.05)$ followed by Least Square Deviation test (Statistica, version 5, 1997). 


\section{RESULTS}

\section{I Cadmium bioaccumulation and trophic transfer rate after 30 days' exposure (Experiment I)}

Average Cd concentrations measured in the whole body organism after 30 days' exposure was $67 \pm 17$ $\mathrm{ng} \cdot \mathrm{g}^{-1}$, fw after control prey ingestion and $229 \pm 13 \mathrm{ng} \cdot \mathrm{g}^{-1}$, fw after contaminated prey consumption. These results highlight the existence of a Cd trophic transfer of $5.3 \pm 0.3 \%$.

$\mathrm{Cd}$ distribution in the different organs of the crayfish is shown in Figure 1. For both of the studied conditions, the classification of the organs, in order of decreasing $\mathrm{Cd}$ concentration is identical: $\mathrm{HP}>>$ intestine, stomach $>$ gills $>>$ green gland $>$ muscle, rest of the body.

After consumption of $C$. fluminea exposed at the contaminated station, the highest concentrations were measured in the hepatopancreas $\left(3340 \pm 335 \mathrm{ng}^{-\mathrm{g}^{-1}}\right.$, fw $), 3.6 \mathrm{x}$ the control values level.

For the stomach and the intestine, the concentrations $-650 \mathrm{ng} \cdot \mathrm{g}^{-1}, \mathrm{fw}$ - are clearly lower than those of HP (x 0.19). Concerning the other organs, the measured levels of accumulation are directly related to Cd transport by the hemolymph, through the digestive barrier. For the whole of the organs except the intestine, the levels of accumulation measured after consumption of the contaminated preys are significantly higher than the levels of reference (Anova test) and represents $37 \%$ of the total bioaccumulated contents, confirming the existence of $\mathrm{Cd}$ trophic transfer.

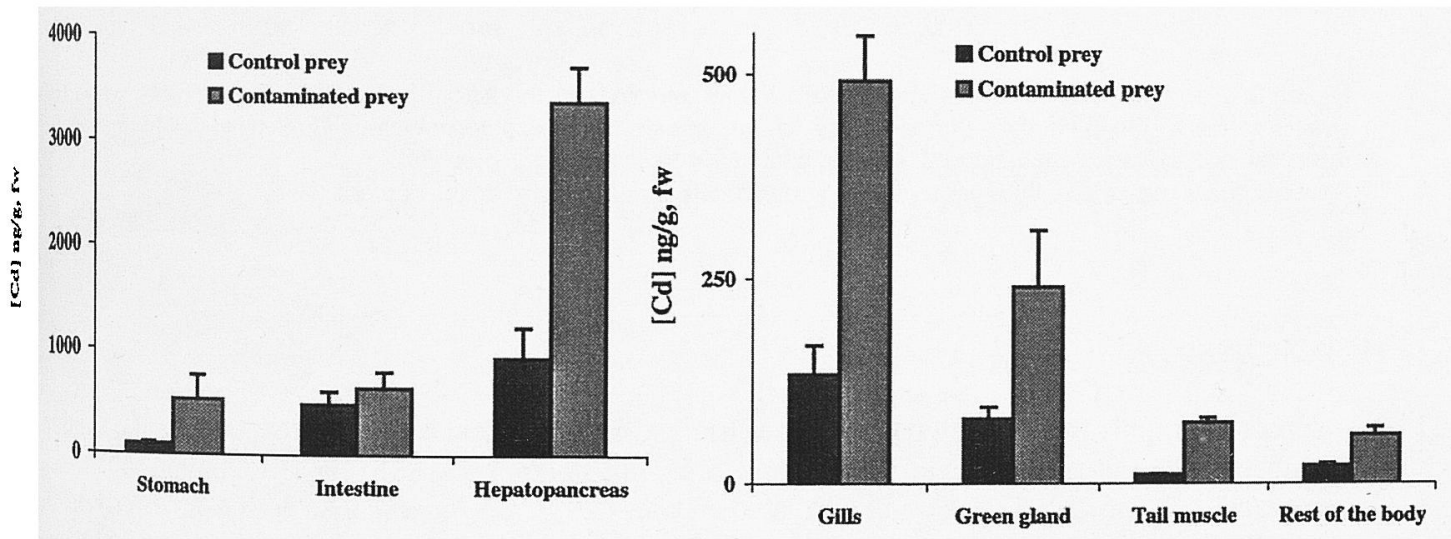

Pigure 1. Cd Average concentrations (ng. $\mathrm{g}^{-1}$, fw) in 7 organs of $A$. astacus after trophic contamination for 30 days 'exposure.

Symbols: mean measured values per replicates and verticals bars : standard errors of mean $(n=3)$.

\section{II Cd bioaccumulation and trophic transfer rate after force-feeding exposure (Experiment In)}

At a whole organism level, 48 hours after the force feeding procedure, average accumulated burden was $613 \pm 131 \mathrm{ng}$-Cd. This represents, $58 \%$ of the Cd initially introduced into the stomach.

Figure 2 shows the average relative burdens (reference levels deducted) after 20/60 minutes and 48 h compared to the quantity of Cd initially introduced into the stomach. After only $20 / 60$ minutes, $15.5 \%$ of the $\mathrm{Cd}$ initially introduced $-184 \mathrm{ng}$ - eliminated by the organism. These results show a very fast intestinal excretion.

As percentage values of the initial contamination burden, $\mathrm{Cd}$ was eliminated (15.5\%), stored in the stomach $(56.4 \%)$ and accumulated in other organs $(28.1 \%)$ such as the hepatopancreas $(6.7 \%)$, the rest 
of the body (13\%) and also the gills (2.6\%); the very fast accumulation observed in the "internal" organs would be related to the nature of the homogenate, accelerating the mechanisms of digestion.

Between $20 / 60$ minutes and $48 \mathrm{~h}$, the relative burden of the stomach decreases clearly (56.4 to $2.7 \%$ ), involving the concomitant increase of the quantities accumulated in the compartment Whole Body. Stomach ( 28 to $47 \%$ ). These results show that the stomach draining involves the contamination of the other organs mainly hepatopancreas, rest of the body and hemolymph, a portion of the $\mathrm{Cd}$ being eliminated. Contents in the other organs - gills, internal, green gland and muscle remain relatively constant.

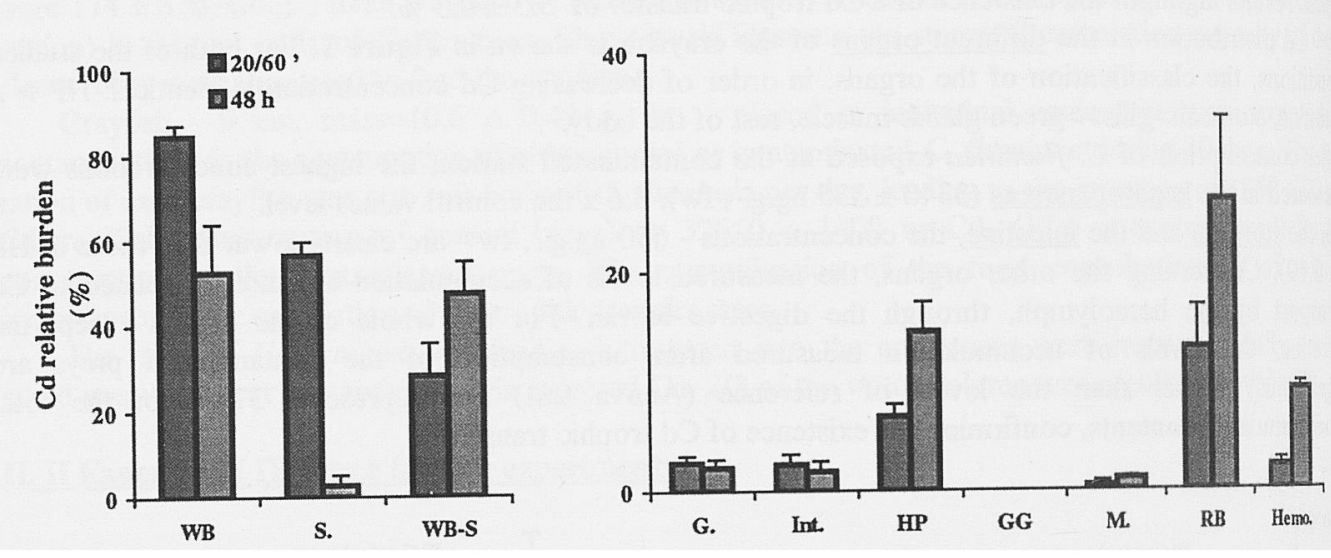

Figure 2. Average relative burdens (\%) (control values deduced) in the whole body -WB-, stomach -S.-, whole body without stomach -WB-S.- and in 7 organs -G.: gills, Int:: intestine, HP: Hepatopancreas, GG: green gland, M.:muscle, RB: rest of the body, Hemo.:hemolymh- 20/60' et 48 hours after force feeding experiment.

Symbols: mean measured values per replicates and verticals bars : standard errors of mean $(n=3)$.

\section{DISCUSSION}

The impact of trophic transfer can be evaluated through transfer rates. Under our experimental conditions (Experiment 1), the transfer rates are low, about $5 \%$, but in comparable to those found in the literature (lower than $10 \%$ ) $[6,12,13]$. Comparable studies with Corbicula fluminealAstacus astacus carried out on methylmercury show a weak transfer rate $-20 \%-[14]$ compared with literature [ 1 ]. Consideing these relatively weak transfer rates, complementary studies (video films) were undertaken to observe the predatory behaviour of crayfish. They revealed that the ingestion of the soft body of $C$. fluminea by crayfish by dilaceration of the soft body with the oral appendices - involved significant losses of food and thus of contaminants as well. Nearly $50 \%$ of the preys' mass might not be ingested by the crayfish. Under these conditions, the transfer rate would then be close to $10 \%$, value still in agreement with the literature. On the other hand, a significant quantity of Cd would be recycled back to the environment and migtt contribute to the contamination of other organisms.

A low transfer rate can nevertheless lead to high bioaccumulation levels - $1200 \mathrm{ng} \mathrm{Cd}$ - considering the significant $\mathrm{Cd}$ burden brought by the elevated consumption of the preys ( $4 \%$ of the crayfish's mass per day). Thus, it seems important to relate internal concentrations of a metal with the transfer rate measured in order to quantify the impact of trophic transfer.

To predict the trophic transfers while considering the "real" quantities of contaminants ingested, 艮 extended our study by using a force feeding technique. This technique showed that the accumulation capacities through the trophic route can be significant - $58 \%$ - after only one meal and a short exposuri time $-48 \mathrm{~h}$-. Thus, decontamination mechanisms by excretion must have been triggered to considerably 
reduce the accumulated contaminants. Metals accumulated in organs are generally bound to intracellular ligands such as MT and MRG [ 5, 15, 16$]$.

Comparison of these 2 approaches uncovers the role of some organs in metal decontamination processes. Under our experimental conditions, successive meals results in $\mathrm{Cd}$ accumulation in the digestive gland $\left(60 \%\right.$ of the relative burden in experiment $\left.\mathrm{I},[\mathrm{HP}]_{\mathrm{Exp} . \mathrm{I}} /[\mathrm{HP}]_{\mathrm{Exp} . \mathrm{II}}=4.8\right)$ confirming the key-role of this organ in the mechanisms of contaminant regulation. These results are in agreement with the literature, indicating that the crayfish's digestive gland has a strong capacity of metal accumulation I storage / detoxification by direct transfer and from food [ 8, 17, 19 ]. Moreover, R-type cells, by their nature and functions, could correspond to a metal storage location [ 20, 21 ]. This could represent a protection / tolerance mechanism, through binding of Cd by the MT [ 22, 23 ]. Al-Mohanna [ 24] showed that copper and zinc are concentrated within intracellular granules in the epithelium of the hepatopancreas of Penaeus semisulcatus for detoxification and $/$ or binding of the metals. The homogenisation (destruction of the tissue structures) of the soft body of Corbicula could on the one hand, make Cd more bioavalable and facilitate $\mathrm{Cd}$ transfer and, on the other hand, increase the fraction of food reaching the hepatopancreas (homogenisation of the tissues results in a $0.1 \mathrm{~mm}$ decrease in food particle size compared with the crumbling of food by gastric digestion).

Moreover, these results show than $\mathrm{Cd}$ crosses the barrier surrounding the digestive gland, reaching the "internal" organs. Among those, we will focus on the muscles. Cd accumulation in the muscles is only observed during experiment I. According to the literature, the muscular compartment is not considered as a Cd storage location; direct exposure experiments carried out on various biological targets - shellfish, fish, ... - in laboratory or in situ (for 30 days) did not lead to the contamination of this compartment. Thus, only ingestion of successive contaminated meals seems to lead to the contamination of the muscular compartment which can, under these conditions, result in Cd transfer along the food chain. The trophic pathway thus leads to the contamination of other predators and to the release of contaminants to the natural environment.

\section{CONCLUSION}

These two approaches lead to very different transfer rate values. These results confirm the absence of a consensus on the role of the trophic pathway in heavy metal accumulation mechanisms for a same species. Thus, the various responses that generated this controversy can be related to the diversity of the experimental approaches - exposure time, "real" quantities ingested by the preys, biological models, ... -. It seems important to develop experimental approaches to reproduce field contamination conditions to evaluate the impact of contamination through the trophic pathway.

\section{References}

[1] Boudou A., et al. "Mercury in the food web: accumulation and transfer mechanisms". Mercury and its effects on Environment and Biology", "Metal ions in biological systems Vol. 34 (A. Sigel \& H. Sigel, 1997), pp. 289-319.

[2] Morel F.M.M., Kraepid A.M.L., and Amyot M. Annu. Rev. Ecol. Syst. 29 (1998) 543-566.

[3] Dallinger R., et al. Oecologia 73 (1987) 91-98.

[4] Wallace W.G., and Lopez G.R. Estuaries 19 (1996) 923-930.

[5] Wallace W.G., Lopez G.R., and Levinton J.S. Mar. Ecol. Prog. Ser. 172 (1998) 225-237.

[6] Olsson P.E., Kling P., and Hogstrand C. "Mechanisms of heavy metal accumulation and toxicity in fish". Metal metabolism in aquatic environments. (W. J. Langston \& M.J. Bebianno, London, 1998) pp. 321-350.

[7] Part P., and Lock R.A.C. Comp. Biochem. Physiol. 76C (1993) 250-263 
[8] Canli M., and Furness R.W. Environ. Toxicol. Chem. 14 (1995) 819-828.

[9] Farag A.M., et al. Environ. Toxicol. Chem. 13 (1994) 2021-2029.

[10] Koyama J., Nanamori N., and Segawa S. Marine Pollution Bulletin 11 (2000) 961-967.

[11] Munger C., and Hare L. Environ. Sci. Technol. 31 (1997) 891-895.

[12] Shaikh Z.A., and Smith J.C. "Metabolism of orally ingested cadmium in humans". Mechanism! of toxicity and hazard evaluation (M. Mercier \& M. Roberfroid, Amsterdam, 1980) pp. 569-574.

[13] W.H.O Cadmium. Environmental Health Criteria, WHO Ed, Geneva 134.1992.

[14] Simon O., and Boudou A. Ecotoxicol. Environ. Saf. (in press).

[15] Baudrimont M., et al. Environ. Toxicol. Chem. 10 (1997) 2096-2105.

[16] Engel D.W., and Brouwer M. Environ. Health. Perpsect. 65 (1986) 87-92.

[17] Devi M., et al. Ecotoxicol. Environ. Saf. 33 (1995) 38-43.

[18] Meyer W., et al. Ecotoxicol. Environ. Saf. 21 (1991) $137^{-1} 56$.

[19]Vogt G. Zoomorphology 114 (1994) $83^{-1} 01$.

[20] Anton A, et al. The Science of the Total Environment 247 (2000) 239-251.

[21] Ceccaldi H.J. Rewiews in Fischeries Sciences 6 (1998) 13-39.

[22] Del Ramo J., et al. .Bull. Environ. Contam. Toxicol. 38 (1987) 736-741.

[23] Roesijadi G. Aquat. Toxicol. 22 (1992) 81-114.

[24] Al-Mohanna S.Y. Crustaceana, 48 (1985) 260-268. 